\title{
BORO EM ARROZ DE TERRAS ALTAS CULTIVADO EM SOLUÇÃO NUTRITIVA $\left({ }^{1}\right)$
}

\author{
PAULO SÉRGIO PAVINATO $\left({ }^{2}\right)$; ALANA AGUIAR $\left({ }^{2}\right)$; GUSTAVO SPADOTTI AMARAL CASTRO $\left({ }^{2}\right)$; \\ CARLOS ALEXANDRE COSTA CRUSCIOL $\left({ }^{3,4^{*}}\right)$
}

\begin{abstract}
RESUMO
O objetivo deste trabalho foi avaliar o efeito de doses de boro na produção de matéria seca e nos parâmetros morfológicos das raízes de duas cultivares de arroz de terras altas. O experimento foi desenvolvido de abril a julho de 2004, em casa de vegetação, em Botucatu (SP), empregando-se duas cultivares de arroz - Caiapó e BRS Talento. As plântulas foram obtidas em condições controladas e após cinco dias, transferidas para vasos de plástico com capacidade para $8 \mathrm{~L}$, utilizando areia lavada como suporte, deixando quatro plantas por vaso. Os tratamentos foram: 0,0;0,5;1,0;2,0;4,0 e 8,0 $\mathrm{mg} \mathrm{L}^{-1} \mathrm{de} \mathrm{B}$, aplicados via solução nutritiva. O corte foi realizado aos 70 dias após o transplante, sendo coletadas parte aérea e sistema radicular separadamente, determinado suas matérias secas e concentrações de $\mathrm{N}$ e B, bem como o comprimento, área superficial e diâmetro médio radicular. Não foi possível obter efeito positivo da aplicação de boro, evidenciando que para a cultura do arroz a dose ótima é a inferior a 0,5 $\mathrm{ml} \mathrm{L}^{-1}$ de B. A aplicação de 3,8 e $3,4 \mathrm{mg} \mathrm{L}^{-1}$ de $\mathrm{B}$ causou efeitos tóxicos às cultivares Caiapó e Talento respectivamente. O limite de toxicidade para raízes das duas cultivares é a concentração de $2,7 \mathrm{mg} \mathrm{L}^{-1}$ de B. Sob toxicidade severa de B as plantas de arroz reduzem expressivamente o comprimento e aumentam o diâmetro radicular, resultando em menor área de absorção de nutrientes.
\end{abstract}

Palavras-chave: Oryza sativa L., doses de boro, nutrição de plantas, produção de matéria seca.

\section{ABSTRACT \\ BORON IN UPLAND RICE CULTIVATED IN NUTRIENT SOLUTION}

The objective of this work was to evaluate the effects of boron rates on dry matter yield and root morphologic parameters of two varieties of upland rice. The experiment was carried out from April to July of 2004, in a greenhouse, in Botucatu, São Paulo State, with two varieties of rice, Caiapó and BRS Talento. The seeds were germinated in a controlled chamber, and five days later, the plants were transplanted in plastic pots of $8 \mathrm{~L}$, being supported by cleaned sand, being kept four plants per pot. The boron rates were $0.0 ; 0.5 ; 1.0 ; 2.0 ; 4.0$ and $8.0 \mathrm{mg}$ of $\mathrm{B} \mathrm{L}^{-1}$, applied via nutrient solution. The harvest was accomplished 70 days after planting, being collected separately the shoot and root, and being determined their dry matter and $\mathrm{N}$ and $\mathrm{B}$ concentrations, as length, surface area and medium diameter of the roots. It was not able to get to the positive effects of boron application, evidencing that, for the rice cropping the optimum rate was lower than $0.5 \mathrm{ml} \mathrm{L}^{-1}$ of $\mathrm{B}$. The application of 3.4 and $3.8 \mathrm{mg} \mathrm{L}^{-1}$ of $\mathrm{B}$ caused toxic effects to the Caiapó and Talento cvs., respectively. The toxic limit for the two cvs. roots is the $2.7 \mathrm{mg} \mathrm{L}^{-}$ ${ }^{1}$ of $\mathrm{B}$ concentration. Under several boron toxic, the plants of rice reduced drastically the length and increased the radicular diameter, resulting in a smaller absorption nutrients area.

Key words: Oryza sativa L., boron rates, plant nutrition, dry matter yield.

${ }^{1}$ ) Recebido para publicação em 5 de dezembro de 2006 e aceito em 5 de março de 2009.

( ${ }^{2}$ ) Programa de Pós-Graduação em Agronomia/Agricultura, Faculdade de Ciências Agronômicas (FCA), Universidade Estadual Paulista (UNESP), Caixa Postal 237, 18603-970 Botucatu (SP). E-mail: pspavinato@fca.unesp.br; alana@fca.unesp.br; gsacastro@fca.unesp.br

( $\left.{ }^{3}\right)$ Departamento de Produção Vegetal, FCA/UNESP, 18603-970 Botucatu (SP). E-mail: crusciol@fca.unesp.br (*) Autor correspondente.

$\left({ }^{4}\right)$ Com bolsa de produtividade do CNPq. 


\section{INTRODUÇÃO}

No Brasil, o cultivo do arroz de terras altas concentra-se na região do cerrado. O cultivo desse cereal na Região Centro-Oeste tem como um dos objetivos a abertura de novas áreas agrícolas, em virtude da tolerância dessa cultura a solos com baixos teores de nutrientes (CRUSCIOL et al., 1999), dentre eles o boro (FAGERIA, 2000).

O boro é um elemento ativador de enzimas que atuam em diversos processos metabólicos, tais como transporte de carboidratos, metabolismo das auxinas e formação de raízes por meio da divisão, alongamento e junção da parede celular e atividade das membranas celulares (MARSCHNER, 1995; LUND et al., 1996; ONO e RODRIGUES, 1996). Dentre suas funções, vale destacar a participação no alongamento celular, por fazer parte dos polissacarídeos da parede celular, sendo sua desordem nutricional prejudicial ao crescimento radicular (Овата, 1995).

O B é um dos micronutrientes mais limitantes à produção vegetal (BROWN e SHELP, 1997), sendo, na faixa de $\mathrm{pH} 4,0$ a 8,0 , absorvido como $\mathrm{H}_{3} \mathrm{BO}_{3}$ e $\mathrm{H}_{2} \mathrm{BO}_{3}{ }^{-}$. Sua disponibilidade no solo afeta significativamente as concentrações nos tecidos vegetais, e seus teores extremamente baixos ou elevados permitem observar nas folhas manifestações visíveis e características desses extremos (Malavolta et al., 1997). Além disso, é um elemento pouco remobilizado na estrutura da maioria das espécies vegetais, independentemente do estágio de desenvolvimento da planta. No entanto, em algumas espécies o B é altamente móvel no floema (plantas que mobilizam B) e, em outras, a remobilização é baixa, ficando dependente do fornecimento deste nutriente por meio da absorção radicular e do transporte via xilema (Dordas et al., 2001).

Em espécies nas quais o B é imóvel, a deficiência ocorre em tecidos de crescimento e sintomas de toxicidade aparecem primeiro em ápices e margens de folhas velhas (DorDAs et al., 2001). O acúmulo de $\mathrm{B}$ em órgãos de plantas é determinado principalmente pela transpiração. Na maioria das espécies de plantas, a concentração de $\mathrm{B}$ aumenta com a idade da folha, e a concentração dentro de uma folha é maior no ápice que na base (Brown e SHelp, 1997).

O boro é exigido em pequenas quantidades pela cultura do arroz, sendo a decisão para aplicar doses adequadas de boro vital para aumentar a produtividade do arroz (FAGERIA, 1998), exigindo-se cautela por ser o intervalo de deficiência e toxicidade bastante estreito (Scivittaro e Machado, 2004). MARSCHNER (1995) cita que a toxicidade de boro é mais comum em regiões áridas ou semiáridas, ou ainda nas relacionadas com água de irrigação com altos teores de B. O mesmo autor cita que o gradiente entre os níveis crítico e tóxico é pequeno e considera, também, que as concentrações tóxicas variam com a espécie vegetal.

As espécies de plantas diferem caracteristicamente quanto ao requerimento de $\mathrm{B}$ para o crescimento. A faixa crítica de deficiência varia de 5 a $10 \mathrm{mg}$ de $B \mathrm{~kg}^{-1}$ de matéria seca de planta (MS) em gramíneas, 20 a $70 \mathrm{mg}$ de $\mathrm{B} \mathrm{kg}^{-1}$ de MS na maioria das dicotiledôneas, e 80 a $100 \mathrm{mg}^{\text {de }} \mathrm{B} \mathrm{kg}^{-1}$ de MS em espécies mais exigentes, como a papoula (MARSCHNER, 1995). Segundo FAGERIa (1984), as folhas de plantas de arroz de terras altas na fase de perfilhamento são diferentemente responsivas à adubação com $B$, a saber: teores de $\mathrm{B}$ menores de $15 \mathrm{mg} \mathrm{kg}^{-1}$ - considerados como deficientes; teores entre 15 e $20 \mathrm{mg} \mathrm{kg}^{-1}$ - críticos; entre $20-100 \mathrm{mg} \mathrm{kg}^{-1}$ - adequados, e, acima de $100 \mathrm{mg}$ $\mathrm{kg}^{-1}-$ tóxicos.

É de fundamental importância o conhecimento de como a cultivar comporta-se na absorção dos nutrientes, em especial o boro, pois existem diferenças interespecíficas para o arroz. Os mecanismos de resposta da cultura de arroz ao boro dependem do genótipo, das diferentes classes de respostas à adubação (Yu et al., 1998), pela capacidade genética diferente, mecanismos ativos e passivos de absorção para o elemento (Dordas e BROWN, 2001), e pela habilidade de mobilizar o complexo B-açúcarálcool através do floema (Bellalou et al., 2003), processos que levam as cultivares à maior adaptação ao meio. Cultivares do grupo moderno, como BRS Talento, são mais exigentes em termos de fertilidade e podem requerer maiores concentrações de boro em relação às cultivares do grupo tradicional, no caso a Caiapó.

Com relação ao metabolismo do nitrogênio, não há ainda evidências concretas do efeito direto do $\mathrm{B}$ neste processo, mas há indícios comprovando que o B exerce mudanças secundárias que afetam a demanda por $\mathrm{N}$ na planta. $\mathrm{O}$ boro atuaria na redução do nitrato e nos conteúdos de aminoácidos e proteínas, que poderiam ser maiores ou menores em plantas deficientes, dependendo da severidade da deficiência, da idade e do órgão da planta (MARSCHNER, 1995).

Sendo o B um elemento ainda pouco explorado com relação ao seu potencial de aumento ou redução na produção das culturas, pela deficiência ou toxicidade, o objetivo deste trabalho foi avaliar o efeito de doses de boro na produção de matéria seca e nos parâmetros morfológicos das raízes de duas cultivares de arroz de terras altas. 


\section{MATERIAL E MÉTODOS}

O experimento foi desenvolvido no período de abril a julho de 2004, em casa de vegetação, em Botucatu (SP). Foram utilizadas duas cultivares de arroz (Oryza sativa L.): Caiapó e BRS Talento. A primeira é considerada cultivar tradicional, pelo porte alto e ser pouco responsiva à adubação. A segunda é relatada como cultivar moderna, com porte menor e boa resposta à adubação, principalmente nitrogenada.

No período de cultivo a temperatura mínima média foi de $18{ }^{\circ} \mathrm{C}$ e a temperatura máxima foi de 28 ${ }^{\circ} \mathrm{C}$ dentro da casa de vegetação.

Plântulas com cinco dias de idade, obtidas em câmara controlada, foram transplantas para vasos de plástico pretos de $8 \mathrm{~L}$, preenchidos com areia grossa peneirada, lavada com ácido clorídrico $0,1 \mathrm{~mol} \mathrm{~L}^{-1} \mathrm{e}$ com água destilada. Foram colocadas, inicialmente, sete plântulas por vaso, e 18 dias após foi realizado desbaste, deixando-se somente as quatro plantas mais vigorosas em cada vaso. O delineamento experimental foi inteiramente casualizado, em arranjo fatorial, composto de duas cultivares combinado com seis doses de B, com quatro repetições.
Os tratamentos foram as concentrações de 0,$0 ; 0,5 ; 1,0 ; 2,0 ; 4,0$ e $8,0 \mathrm{mg} \mathrm{L}^{-1}$ de $\mathrm{B}$, sendo aplicados por meio do fornecimento de solução nutritiva. A menor dose de boro utilizada é equivalente à sugerida por HoAgLAND e ARNON (1950). A aplicação da solução nutritiva foi realizada diariamente, diretamente na superfície do substrato, no volume de $200 \mathrm{~mL}$ por vaso. O início da aplicação foi no terceiro dia após o transplante e, nos primeiros 15 dias, a solução foi aplicada com "meia força", ou seja, a metade da concentração dos nutrientes, com exceção do B. O excesso de solução percolou naturalmente para fora do vaso, pois em dias nublados, com temperaturas inferiores e com menor evapotranspiração ocorre menor absorção de líquido pelas plantas. A solução utilizada foi a de FURLANi e FurLani (1988), com pequenas alterações na concentração dos nutrientes, com valores descritos na tabela 1. A solução nutritiva foi composta por água deionizada e pelos reagentes químicos nas formas p.a. descritos a seguir: $\left(\mathrm{NH}_{4}\right)_{2} \mathrm{SO}_{4}, \mathrm{Ca}\left(\mathrm{NO}_{3}\right)_{2} \cdot 4 \mathrm{H}_{2} \mathrm{O}, \mathrm{CaCl}_{2} \cdot 2 \mathrm{H}_{2} \mathrm{O}, \mathrm{K}_{2} \mathrm{SO}_{4}$, $\mathrm{MgSO}_{4} .7 \mathrm{H}_{2} \mathrm{O}, \mathrm{KH}_{2} \mathrm{PO}_{4}, \mathrm{MnCl}_{2} .4 \mathrm{H}_{2} \mathrm{O}, \mathrm{H}_{3} \mathrm{BO}_{3}$, $\mathrm{ZnSO}_{4} \cdot 7 \mathrm{H}_{2} \mathrm{O}, \mathrm{CuSO}_{4} \cdot 5 \mathrm{H}_{2} \mathrm{O},\left(\mathrm{NH}_{4}\right)_{6} \mathrm{Mo}_{7} \mathrm{O}_{24} \cdot 4 \mathrm{H}_{2} \mathrm{O}$ e o produto comercial Ferrilene ${ }^{\circledR}(\mathrm{FeEDDHA}-6 \% \mathrm{Fe})$.

Tabela 1. Concentrações de nutrientes na solução nutritiva utilizada para cultivo das cultivares de arroz em casa de vegetação

\begin{tabular}{lccc}
\hline Nutriente & Concentração & Nutriente & Concentração \\
\hline & $\mathrm{mg} \mathrm{L}$ L $^{-1}$ & & $\mathrm{mg} \mathrm{L}^{-1}$ \\
$\mathrm{~N}-\mathrm{NO}_{3^{-}}$ & 48 & $\mathrm{Cl}$ & 220 \\
$\mathrm{~N}-\mathrm{NH}^{4}+$ & 12 & $\mathrm{Fe}$ & 5 \\
$\mathrm{Ca}$ & 192 & $\mathrm{Mn}$ & 0,67 \\
$\mathrm{~K}$ & 185 & $\mathrm{Zn}$ & 0,20 \\
$\mathrm{Mg}$ & 40 & $\mathrm{Cu}$ & 0,05 \\
$\mathrm{P}$ & 8 & $\mathrm{Mo}$ & 0,14 \\
$\mathrm{~S}$ & 139 & & \\
\hline
\end{tabular}

Aos 38 e aos 70 dias após o transplante, procederam-se avaliações do perfilhamento dos cultivares, sendo realizada a contagem dos perfilhos efetivamente desenvolvidos em cada planta. A colheita do experimento foi realizada aos 70 dias após o transplante, coletando-se a parte aérea e o sistema radicular. A parte aérea das plantas de cada vaso foi seca em estufa a cerca de $65^{\circ} \mathrm{C}$ até massa constante, sendo assim determinada a matéria seca total e avaliadas concentrações totais de $\mathrm{N}$ e $\mathrm{B}$ no tecido após moagem do material (TEDESCO, 1995).

O sistema radicular foi separado em dois grupos: (a) as raízes de três plantas foram colocadas para secar a cerca de $65{ }^{\circ} \mathrm{C}$, determinando-se, posteriormente, a matéria seca e as concentrações totais de $\mathrm{N}$ e $\mathrm{B}$ no tecido, seguindo a mesma metodologia empregada para a análise desses nutrientes na parte aérea das plantas; (b) o sistema radicular da quarta planta de cada vaso foi armazenado em solução de etanol a 30\%, em geladeira a cerca de $0{ }^{\circ} \mathrm{C}$, para posterior determinação do comprimento, da área superficial e do diâmetro médio de raízes (parâmetros morfológicos das raízes), através de leitura em scanner e auxílio do programa computacional WinRHIZO.

Os resultados foram submetidos à análise da variância. Para cultivares utilizou-se a comparação de médias pelo teste de Tukey a 5\% de probabilidade. Para doses de $\mathrm{B}$ os resultados foram submetidos à análise de regressão polinomial a $5 \%$ de probabilidade pelo teste $\mathrm{F}$. 
Para interação cultivares $\mathrm{X}$ doses de B adotouse, no desdobramento, a comparação de médias para cultivares (teste de Tukey a $5 \%$ de probabilidade) e a análise de regressão polinomial (5\% de probabilidade pelo teste F) para doses.

\section{RESULTADOS E DISCUSSÃO}

Analisando os resultados constatou-se que houve interação Cultivar $x$ Doses para as variáveis: número de perfilhos por plantas aos 38 e 70 dias após o transplante (Figura 1a,b), matéria seca total e da parte aérea aos 70 dias após o transplante (Figura 1e, c), teor de nitrogênio e teor de boro na matéria seca de parte aérea (Figura 2a,b), acúmulo de boro na parte aérea e na raiz (Figura $2 \mathrm{~d}$,e) e diâmetro médio na raiz (Figura 3b). As demais variáveis só foram influenciadas pelas doses de boro.

O número de perfilhos por planta, tanto aos 38 quanto aos 70 dias após o transplante, foi influenciado pelas concentrações de B nas duas cultivares avaliadas (Figura 1a,b). A cultivar Caiapó proporcionou menor número de perfilhos que BRS Talento, sendo, entretanto, uma característica inerente a essa cultivar ter menos perfilhos, compensando, porém, com maior produção de matéria seca. Observou-se também que, quanto maior o nível de $\mathrm{B}$ menor o número de perfilhos para as duas cultivares, nas duas épocas de avaliação. Esse fato comprova que houve toxicidade de B com as concentrações utilizadas no experimento, prejudicando a formação de novos perfilhos no arroz. O efeito mais depressivo na redução do número de perfilhos foi com a concentração de $8 \mathrm{mg} \mathrm{L}^{-1}$ de B, embora as concentrações menores de $B$ também tenham prejudicado este componente.

A redução no número de perfilhos observada neste trabalho e a consequente queda no número de panículas por área gerada pelo menor número de colmos poderiam ocasionar na redução da produtividade desta cultura.

A produção de matéria seca da parte aérea foi semelhante ao número de perfilhos, ou seja, com a aplicação de até $4 \mathrm{mg} \mathrm{L}^{-1}$ de $B$ não houve redução expressiva na produção; com a aplicação de $8 \mathrm{mg} \mathrm{L}^{-1}$ de $\mathrm{B}$, a redução foi de 52 e $45 \%$ para as cultivares Caiapó e Talento, respectivamente, em relação à produção máxima de cada cultivar (Figura 1c). Devido aos elevados valores de produção de matéria seca de parte aérea, a cultivar Caiapó proporcionou maior produção total de matéria seca que Talento (Figura 1e), o inverso do observado para o número de perfilhos, concordando com a afirmação de ser este um comportamento próprio das cultivares.

Avaliando, por meio da produção de matéria seca em dois cultivos, Mascarenhas et al. (1998) obtiveram dados semelhantes, em outra cultura, aos apresentados neste trabalho, ou seja, verificaram queda linear na produção de matéria seca na cultura do feijoeiro submetidos à aplicação de doses de 0 até $16 \mathrm{~kg} \mathrm{ha}^{-1}$ de $\mathrm{B}$, em solo com pH $\mathrm{CaCl}_{2}$ de 6,3.
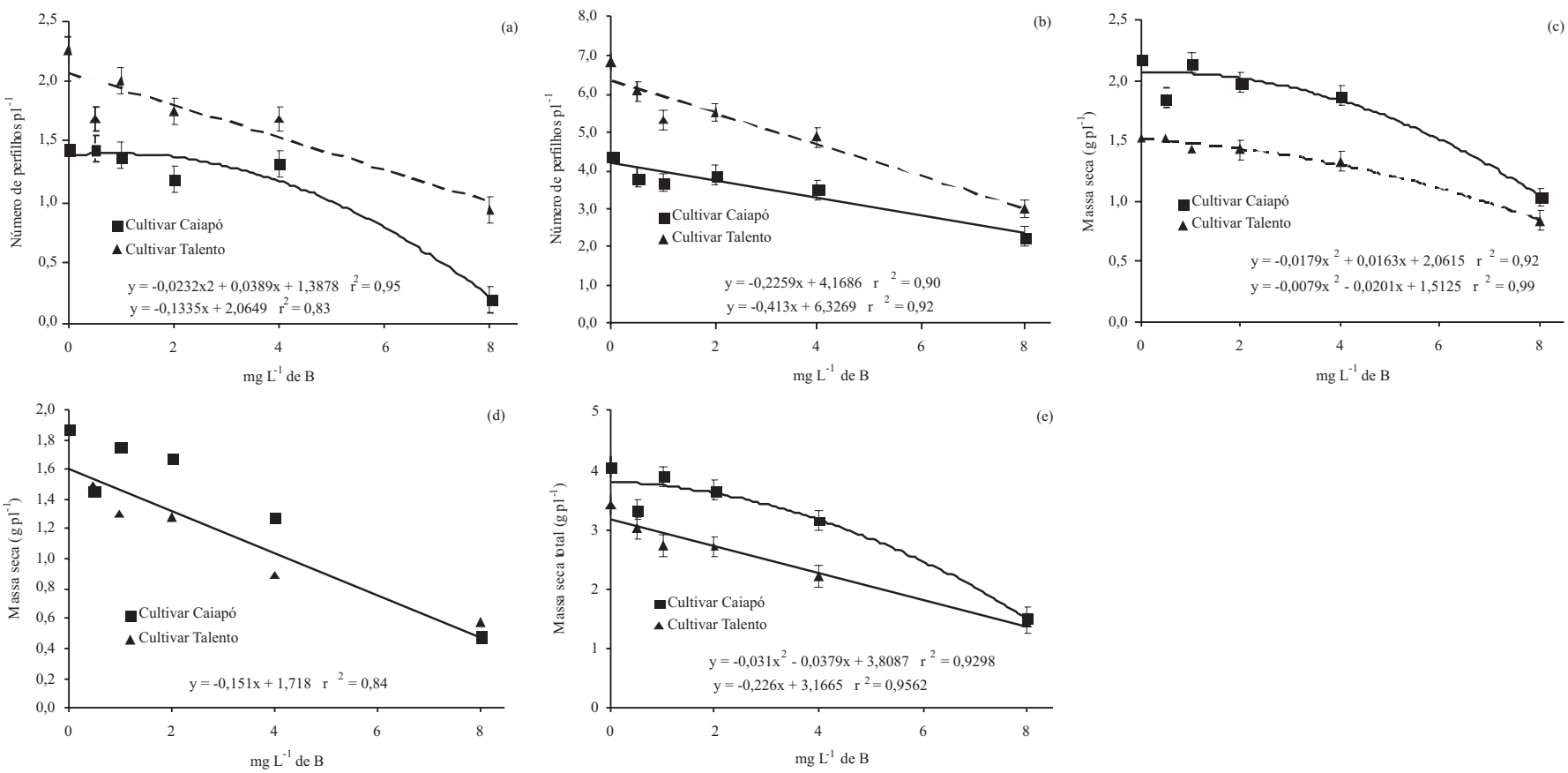

Figura 1. Número de perfilhos por planta aos 38 (a) e aos 70 dias (b) após o transplante e produção de matéria seca na parte aérea (c), no sistema radicular (d) e na planta inteira (e) em duas cultivares de arroz. Barras verticais nos gráficos indicam a DMS, diferença mínima significativa, entre as cultivares pelo teste de Tukey $(p<0,05)$. 
Em relação à produção de matéria seca do sistema radicular, não houve diferença significativa entre as cultivares (Figura 1d). Observou-se, porém, a mesma tendência ocorrida para a matéria seca na parte aérea, ou seja, diminuição da matéria seca radicular com o aumento das concentrações de B, chegando a reduzir em torno de $70 \%$ com a concentração de $8 \mathrm{mg} \mathrm{L}^{-1}$ de B. O sistema radicular do arroz é pouco sensível à deficiência de $B$, necessitando o mínimo para seu crescimento (FAGERIA, 2000), o que explica não ter havido resposta positiva às menores concentrações de $B$ aplicadas neste experimento. Por este motivo, e com os resultados observados, acredita-se que com a utilização de doses inferiores à menor aplicada neste trabalho, poderia haver resposta positiva à aplicação deste micronutriente no arroz. Sugerem-se estudos com doses inferiores a $0,5 \mathrm{mg} \mathrm{L}^{-1} \mathrm{de} \mathrm{B}$, a fim de se obter uma concentração ideal com o respectivo teor na parte aérea.

Outra possibilidade é que tenha havido aporte de $B$, oriundo da semente, suficiente para o desenvolvimento adequado das plantas até o estágio de avaliação. Furlani et al. (2003), trabalhando com trigo e também usando soluções purificadas e água deionizada, não conseguiram detectar deficiência severa que inibisse o crescimento radicular e a formação xilemática nos tratamentos sem $B$, mas não conseguiram boa formação da espiga e o enchimento de grãos.

A concentração de nitrogênio na parte aérea do arroz aumentou de acordo com as concentrações de $B$ na solução nutritiva (Figura 2a), sendo este incremento mais significativo para a cultivar Caiapó, mostrando que pode ter ocorrido maior síntese proteica e acúmulo de $\mathrm{N}$ pela maior concentração de $B$, não necessariamente representando melhor resultado no desenvolvimento da cultura. Sabe-se que o B participa de processos que envolvem os compostos nitrogenados na síntese protéica (DUGGER, 1983), portanto o fornecimento de boro pode ter estimulado a maior absorção de $\mathrm{N}$ pela cultura.

Por outro lado, a menor concentração de $\mathrm{N}$ na cultivar Caiapó na testemunha e nas menores doses de B pode ser explicada pelo efeito diluição, pois a matéria seca acumulada nesses tratamentos foi bem maior que na maior dose de B; além disso, a do B está diretamente relacionada com o crescimento da parte aérea das plantas, onde ocorre efetivamente a formação da clorofila e síntese protéica, processos que o N é componente básico (MARSCHNER, 1995). Na média dos tratamentos e das duas cultivares, a concentração de $\mathrm{N}$ no sistema radicular foi de 13,5 $\mathrm{g} \mathrm{kg}^{-1}$ de MS, semelhante ao obtido por CunHA (2006) com arroz irrigado.
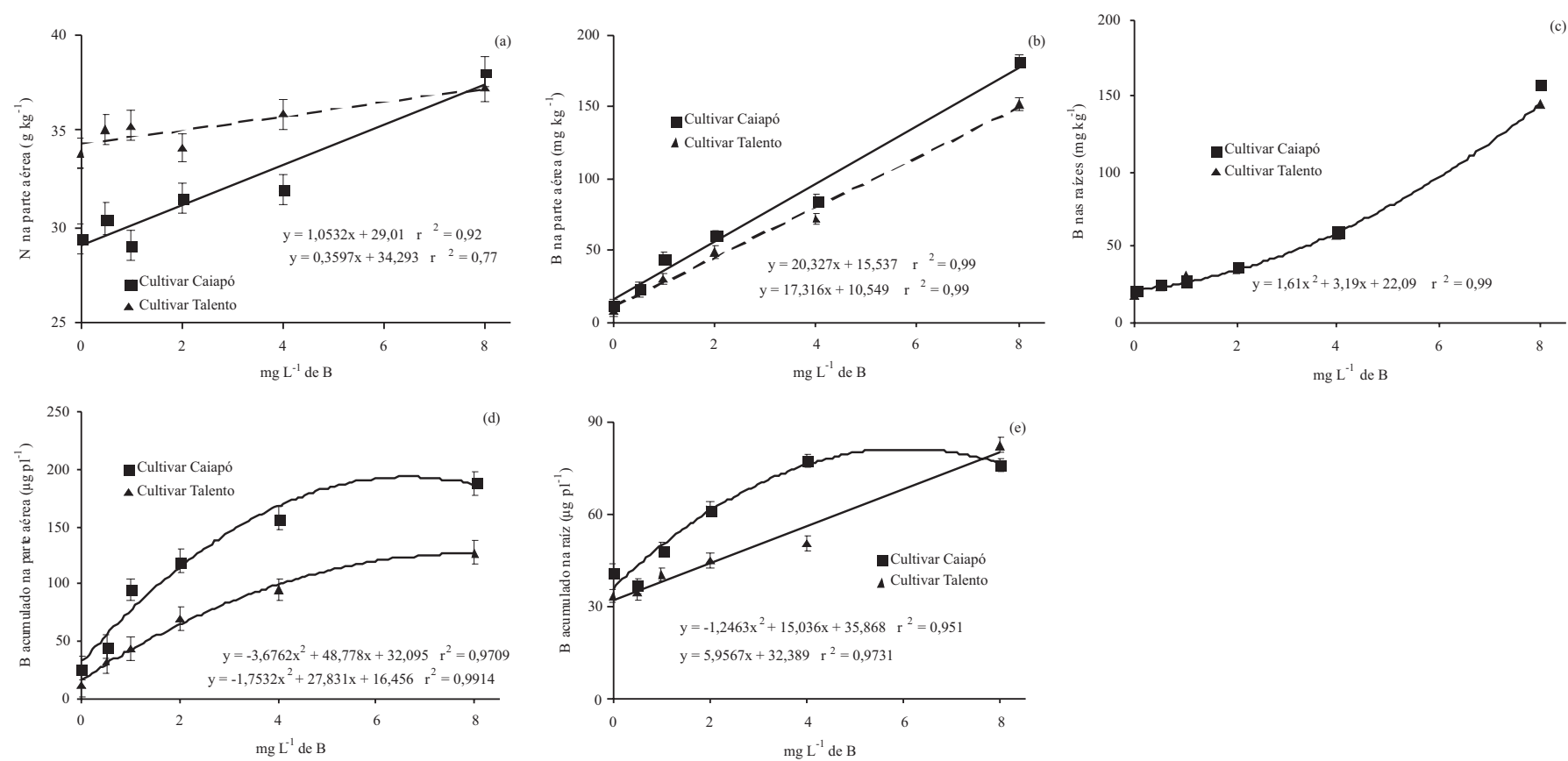

Figura 2. Concentrações de nitrogênio (a) e de boro na parte aérea (b) e no sistema radicular (c) e boro acumulado na parte aérea (d) e na raiz (e) de duas cultivares de arroz aos 70 dias após transplante. Barras verticais nos gráficos indicam a DMS, diferença mínima significativa, entre as cultivares pelo teste de Tukey $(\mathrm{p}<0,05)$. 
A concentração de B na parte aérea observada neste trabalho aumentou linearmente com as doses deste nutriente (Figura $2 \mathrm{~b}$ ), para as duas cultivares avaliadas, chegando a atingir $182 \mathrm{mg} \mathrm{kg}^{-1}$ de MS na cultivar Caiapó com a aplicação de $8 \mathrm{mg} \mathrm{de} \mathrm{B} \mathrm{L}^{-1}$ muito acima das concentrações normais sugeridas por FAGERIA (2000). Para a cultura do arroz, o mesmo autor cita que o nível considerado adequado na parte aérea é de $20 \mathrm{mg} \mathrm{kg}^{-1}$ de MS.

Esse aumento na concentração de $B$ nas plantas exerceu efeito sobre a concentração de $\mathrm{N}$ na parte aérea, como citado anteriormente, pois o B, estando em excesso, ocasiona desbalanço nutricional que interfere na síntese de proteínas e afeta diretamente o metabolismo do N (DUGGER, 1983).

Nos dados obtidos neste trabalho, observouse que a maior produção de matéria seca foi obtida sem aplicação de $B$, nas duas cultivares. A aplicação de 3,8 e 3,4 $\mathrm{mg} \mathrm{L}^{-1}$ de $B$ reduziu em até $10 \%$ a produção de matéria seca, com concentrações no tecido de 93 e $69 \mathrm{mg} \mathrm{kg}^{-1}$ de MS, para as cultivares Caiapó e Talento respectivamente. Esses valores podem ser considerados como os limites de toxicidade para essas cultivares. Maiores concentrações provavelmente ocasionariam queda na produtividade de grãos da cultura pela redução dos componentes produtivos do arroz, como perfilhamento e, consequentemente, o número de panículas por metro.

Pelas curvas ajustadas, a máxima produção de matéria seca seria obtida com 0,44 $\mathrm{mg} \mathrm{L}^{-1}$ de B para a cultivar Caiapó; a cultivar Talento não foi positivamente responsiva à aplicação de B.

De acordo com Furlani et al. (2003), as concentrações de B aumentaram na parte aérea do trigo conforme o aumento da dose aplicada deste nutriente, atingindo até $318 \mathrm{mg} \mathrm{kg}^{-1}$ de MS nas folhas com a aplicação de 2,0 $\mathrm{mg} \mathrm{L}^{-1}$ de $B$ em solução nutritiva. O nível crítico de deficiência de $\mathrm{B}$ no trigo foi de $25 \mathrm{mg} \mathrm{kg}^{-1}$ na parte aérea e o limite crítico de toxicidade variou de 44 a $318 \mathrm{mg} \mathrm{kg}^{-1}$, dependendo da cultivar.

Quanto aos níveis críticos inferiores, PAULA (1995) observou valores entre 17 e $35 \mathrm{mg} \mathrm{kg}^{-1}$ de B na parte aérea do arroz durante o florescimento, cultivado em solos de várzea sob inundação.

O mesmo autor menciona que o nível de toxicidade deve estar acima de $51 \mathrm{mg} \mathrm{kg}^{-1}$ de B, a maior concentração de $B$ no tecido foliar, sem a observação de sintomas de toxicidade, embora tenha havido redução na produção de matéria seca com esta dose.
RAIJ et al. (1996) citam que, para todas as folhas de arroz amostradas no florescimento, a faixa adequada é de 15 a $26 \mathrm{mg}$ de $\mathrm{B} \mathrm{kg}^{-1}$ de MS.

Nas duas cultivares, as concentrações de B foram semelhantes nas raízes (Figura 2c). A concentração aumentou com a dose de B aplicada, variando de $17,8 \mathrm{mg} \mathrm{kg}^{-1}$ na testemunha a 157,6 $\mathrm{mg} \mathrm{kg}^{-1}$ na dose de $8 \mathrm{mg} \mathrm{L}^{-1}$ de B. Com a curva ajustada, a matéria seca do sistema radicular teria redução de até $10 \%$ com a dose de $1,1 \mathrm{mg} \mathrm{L}^{-1}$ de B. o que representa concentração nas raízes de $27,5 \mathrm{mg} \mathrm{kg}^{-1}$ de MS; concentrações acima desse valor limitariam o bom desenvolvimento da planta.

Quanto ao acúmulo de boro na parte aérea (Figura 2d) e nas raízes das plantas de arroz (Figura 2e), foram observados valores superiores na cultivar Caiapó em relação à cultivar Talento.

$\mathrm{O}$ acúmulo de boro foi maior na parte aérea, variando de 12 a $128 \mu \mathrm{g}$ por planta na cultivar Talento e de 27 a $189 \mu \mathrm{g}$ por planta na Caiapó. Considerando o acúmulo nas raízes, a variação foi de 33 a $82 \mu \mathrm{g}$ por planta e de 41 a $76 \mu \mathrm{g}$ por planta nas cultivares Talento e Caiapó respectivamente. Ressalta-se que o total acumulado por planta de arroz foi crescente, apesar da redução da matéria seca de parte aérea e raiz. Esse resultado foi decorrente da elevação dos teores de boro proporcionado pela elevação das doses de $B$, evidenciando acúmulo tóxico em ambas as secções avaliadas.

O comprimento (Figura 3a) e a área do sistema radicular apresentaram comportamento semelhante entre os duas cultivares, mostrando a mesma tendência da matéria seca das raízes, ou seja, foi maior na testemunha e decresceu progressivamente com o aumento da concentração de B. Com a concentração de $2,7 \mathrm{mg} \mathrm{L}^{-1}$ de B ocorreria a redução de até $10 \%$ no comprimento do sistema radicular. Concentrações maiores que esta ocasionariam acentuada redução do comprimento do sistema radicular, o que poderia comprometer a produtividade da cultura.

A concentração de B na solução influenciou o diâmetro médio das raízes das duas cultivares de arroz (Figura 3b). Em ambas, houve aumento do diâmetro médio com o aumento da concentração. Como observado visualmente no momento da lavagem das raízes, as concentrações mais elevadas de B proporcionaram raízes mais grossas, ocasionando menor área de absorção, possivelmente aumentando a suscetibilidade ao estresse por água e nutrientes nas plantas em condições de campo. 

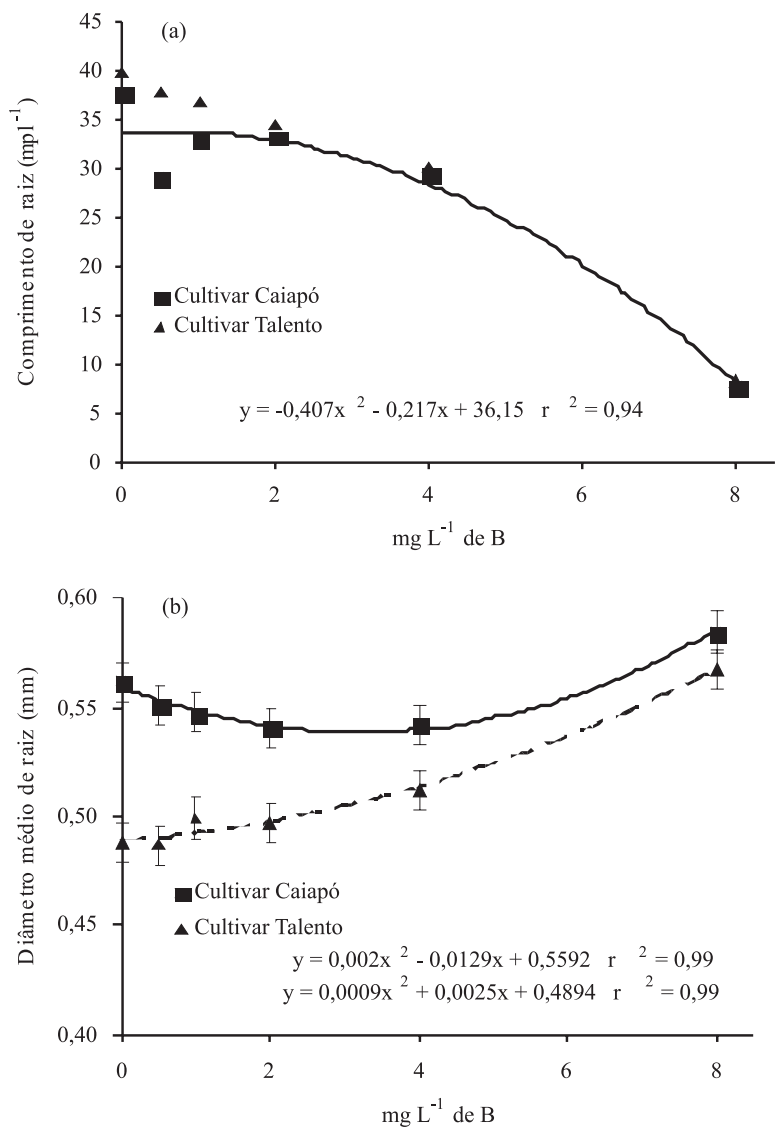

Figura 3. Comprimento radicular (a) e diâmetro médio de raiz (b) de duas cultivares de arroz aos 70 dias após transplante. Barras verticais nos gráficos indicam a DMS, diferença mínima significativa, entre as cultivares pelo teste de Tukey $(p<0,05)$.

\section{CONCLUSÕES}

1. Não foi possível obter, com as doses estudadas, efeito positivo da aplicação de boro, evidenciando que para a cultura do arroz a dose ótima é inferior a $0,5 \mathrm{~mL} \mathrm{~L}^{-1}$ de $\mathrm{B}$.

2. A aplicação de 3,8 e $3,4 \mathrm{mg} \mathrm{L}^{-1}$ de $B$ proporciona concentração de 93 e $69 \mathrm{mg} \mathrm{kg}^{-1}$ de B na matéria seca de plantas de arroz, causando efeitos tóxicos às cultivares Caiapó e Talento respectivamente.

3. O sistema radicular não difere entre as cultivares Caiapó e Talento para comprimento e área, porém Cultivar Caiapó possui maior diâmetro médio radicular. O limite de toxicidade para raízes das duas cultivares é a concentração de $2,7 \mathrm{mg} \mathrm{L}^{-1}$ de B.

4. Sob toxicidade severa de $B$ as plantas de arroz reduzem expressivamente o comprimento e aumentam o diâmetro radicular, resultando em menor área de absorção de nutrientes.

\section{REFERÊNCIAS}

BELLALOUI, N.; YADAVC, R.C.; CHERN, M.S.; HU, H.; GILLEN, A.M.; GREVE, C.; DANDEKAN, A.M.; RONALD, P.C.; BROWN, P.C. Transgenically enhanced sorbitol synthesis facilitates phloem-boron mobility in rice. Physiologia Plantarum, v.117, p.79-84, 2003.

BROWN, P. H.; SHELP, B. J. Boron mobility in plants. The Hague, Plant and Soil, v.193, p.85-101, 1997.

CRUSCIOL, C.A.C.; MACHADO, J.R.; ARF, O.; RODRIGUES, A.F. Matéria seca e absorção de nutrientes em função do espaçamento e da densidade de semeadura em arroz de terras alta. Scientia Agricola, v.5, p.63-70, 1999.

CUNHA, U.S.; CARBONARI, J.J; VENDRAMIM, J.D.; MARTINS, J.F.S. Associação entre teor de nitrogênio em cultivares de arroz e ataque de Oryzophagus oryzae (Costa Lima) (Coleoptera: Curculionidae). Ciência Rural , v. 36, p.16711677, 2006 .

DORDAS, C. \& BROWN, P.H. Evidence mediated channel in transport of boric acid in Squash. Plant and Soil, 235:95-103, 2001.

DORDAS, C.; SAH, R.; BROWN, P. H.; ZENG, Q.; HU, H. Remobilização de micronutrientes e elementos tóxicos em plantas superiores. In: FERREIRA, M. E.; CRUZ, M. C. P.; RAIJ, B. van; ABREU, C. A. (Ed.). Micronutrientes e elementos tóxicos na agricultura. Jaboticabal: CNPq/FAPESP/ POTAFOS, 2001. p.43-70.

DUGGER, W. M. Boron in plant metabolism. In: LÄUCHLI, A.; BIELISKI, R. L. (Ed.). Inorganic plant nutrition. Berlin: Springer-Verlag, 1983. p.623-650.

FAGERIA, N.K. Resposta de cultivares de arroz à aplicação de calcário em solo de cerrado. Pesquisa Agropecuária Brasileira, v.19, p.883-889, jul. 1984.

FAGERIA, N.K. Manejo da calagem e adubação do arroz In: BRESEGHELLO, F.; STONE, L.F. Tecnologia para o arroz de terras altas. Santo Antônio de Goiás: Embrapa Arroz e Feijão, 1998. p.67-78.

FAGERIA, N.K. Níveis adequados e tóxicos de boro na produção de arroz, feijão, milho, soja e trigo em solo de cerrado. Revista Brasileira de Engenharia Agrícola e Ambiental, v.4, p.57-62, 2000.

FURLANI, A.M.C.; CARVALHO, C.P.; FREITAS, J.G.; VERDIAL, M.F. Wheat cultivar tolerance to boron deficiency and toxicity in nutrient solution. Scientia Agricola, v.60, p.359370, 2003.

FURLANI, A.M.C.; FURLANI, P.R. Composição e pH de soluções nutritivas para estudos fisiológicos e seleção de plantas em condições nutricionais adversas. Campinas: Instituto Agronômico, 1988. 34p. (Boletim Técnico, 121)

HOAGLAND, D.R.; ARNON, D.J. The water culture method for growing plants without soil. California Agricultural Experiment Station, 1950. 32p. (Circular, 347) 
LUND, S.T.; SMITH, A.G.; HACKETT, W.P. Cuttings of tabacco mutant, rac, undergo cell divisions but do not initiate adventitious roots inresponse to exogenous auxina. Physiologia Plantarum, v.97, p.372-380, 1996.

MALAVOLTA, E.; VITTI, G.C.; OLIVEIRA, S.A. Avaliação do estado nutricional das plantas: princípios e aplicações. 2.ed. Piracicaba: POTAFOS, 1997.319p.

MARSCHNER, H. Mineral nutrition of higher plants. San Diego, Academic, 1995. 889p.

MASCARENHAS, H.A.A.; TANAKA, R.T.; NOGUEIRA, S.S.S.; CARMELLO, Q.A.C.; AMBROSANO, E.J. Resposta do feijoeiro a doses de boro em cultivo de inverno e de primavera. Bragantia, v.57, p.387-392, 1998.

OBATA, H. Micro essential elements. In: MATSUO, T.; KUMAZAWA, K.; ISHII, R.; ISHIHARA, K.; HIRATA, H. (Ed.). Science of the rice plant - volume two - physiology. Tokyo: Food and Agriculture Police Research Center, 1995. p.402-417.

ONO, E.O.; RODRIGUES, J.D. Aspecto da fisiologia do enraizamento de estacas caulinares. Jaboticabal, Universidade Estadual Paulista, 1996. 83p.

PAULA, M.B. Eficiência de extratores e níveis críticos de boro disponível em amostras de solos aluviais e hidromórficos sob a cultura do arroz inundado. 1995. 69p. Tese (Doutorado) - Universidade Federal de Lavras, Lavras.

RAIJ, B. van.; CANTARELLA, H.; QUAGGIO, J.A.; FURLANI, A.M.C. (Ed.). Recomendações de adubação e calagem para o Estado de São Paulo. Campinas: Instituto Agronômico, 1996. 285p. (Boletim Técnico, 100).

SCIVITTARO, W.B.; MACHADO, O.M. Adubação e calagem para a cultura do arroz irrigado. In: GOMES, A.S.; MAGALHÃES JUNIOR, A.M. (Ed.). Arroz irrigado no sul do Brasil. Brasília: Embrapa Informações Tecnológicas, 2004. p.259-297.

TEDESCO, M. J.; GIANELLO, C.; BISSANI, C. A.; BOHNEN, H.; VOLKWEISS, S. J. Análises de solo, plantas e outros materiais. 2 ed. Porto Alegre: Universidade Federal de Rio Grande do Sul, 1995. 174p.

YU, P.; HUBER, J.T.; SANTOS, F.A.P. Effects of ground, steamflaked, and steam-rolled corn grains on performance of lactating dairy cows. Journal of Dairy Science, v.81, n.3, p.777783, 1998. 